\title{
A Homeopathic View of the Influence of Chronic Diseases in the Manifestation of COVID-19
}

\author{
Fernanda Maria Simões da Costa Fujino ${ }^{1}$ Ana Amélia Campos Claro Olandim ${ }^{1}$ Vagner Doja Barnabé ${ }^{1}$ \\ Jennifer Anne Coggan ${ }^{1}$ Nilson Roberti Benites ${ }^{2}$
}

${ }^{1}$ Instituto Hahnemanniano George Galvão (IHGG), São Paulo, Brazil

2 Department of Preventive Veterinary Medicine and Animal Health (VPS), University of São Paulo, School of Veterinary Medicine and Animal Science, São Paulo, Brazil
Address for correspondence Fernanda Maria Simões da Costa Fujino, Instituto Hahnemanniano George Galvão (IHGG), Rua Dionísio da Costa, 410-apto. 122, Vila Mariana, São Paulo, SP 04117-110, Brazil (e-mail: fernandamscosta@gmail.com).

Homeopathy 2021;110:67-69.

\begin{abstract}
Keywords

- COVID-19

- homeopathy

- chronic disease

COVID-19 (coronavirus disease 2019) may present variable symptoms among infected individuals, with chronic disease patients appearing as the group most susceptible to present severe pulmonary infection, while having a higher risk of developing complications from the disease. This study demonstrates the relationship between the manifestation of COVID-19 and the presence of chronic miasmatic disease, based on the works of Samuel Hahnemann. The reaction of the individual who previously presented chronic miasmatic disease, when in contact with the stimulus of the epidemic disease, depends on the type of response that the organism was generating in the face of the pre-existing situation: if it is an intense reaction and greater than that which the stimulus of COVID-19 can generate, this individual will not develop the severe form of the epidemic disease; if the reaction is less than that generated by COVID-19, more intense symptoms may appear. Understanding that the presence of a chronic miasmatic disease interferes with the manifestation of COVID-19, which may have repercussions on other organs, can change how one must act on the treatment, as this can alter the individual's health status.
\end{abstract}

\section{Introduction}

A new variant of coronavirus was isolated in January 2020, named severe acute respiratory syndrome coronavirus 2 (SARS-CoV-2). The condition caused by this virus was called coronavirus disease 2019 (COVID-19) ${ }^{1}$ and stands out for its speed of global dissemination, for its severity, and for the difficulties in its containment, which is why it was declared a pandemic on March 11, 2020 by the World Health Organization (WHO). ${ }^{2}$

COVID-19 has variable symptoms, with the elderly and those with chronic diseases, such as systemic arterial hypertension, diabetes mellitus, lung, heart or kidney diseases, cancer, and immunosuppressed individuals being more sus-

received

June 29, 2020

accepted after revision

August 24, 2020

published online

January 22, 2021 ceptible to severe pulmonary infection. ${ }^{3,4}$ These patients may represent 25 to $50 \%$ of those infected and have higher mortality rates. ${ }^{3}$ Obesity and smoking are also considered risk factors for COVID-19 complications. ${ }^{5}$

Hahnemann's writings ${ }^{6,7}$ were used here to elucidate this relationship between the development of the most severe cases of COVID-19 and the presence of chronic disease.

Hahnemann states that if the individual does not have a chronic miasmatic disease, he or she is more likely to develop acute epidemic diseases. ${ }^{8}$ When someone's vitality is disturbed, they become sick. The disease sets in before the changes in the sensations and functions of the organism appear, and when they occur, they start to characterize a disease: that is, there are signs and symptoms. ${ }^{9}$

(c) 2021. The Faculty of Homeopathy.

All rights reserved.

Georg Thieme Verlag KG,

Rüdigerstraße 14,

70469 Stuttgart, Germany
DOI https://doi.org/ 10.1055/s-0040-1718746. ISSN $1475-4916$. 


\section{Interference of a Miasmatic Disease}

Hahnemann exposes the three different situations that can occur in nature when two dissimilar disease processes are found in an individual:

1. "If the two dissimilar diseases meeting together in the human being be of equal strength, or still more if the older one be the stronger, the new disease will be repelled by the old one from the body and not allowed to affect it. A patient suffering from a severe chronic disease will not be infected by a moderate autumnal dysentery or other epidemic disease. The plague of the Levant, according to Larry, does not break out where scurvy is prevalent, and persons suffering from eczema are not infected by it. Rachitis, Jenner alleges, prevents vaccination from taking effect. Those suffering from pulmonary consumption are not liable to be attacked by epidemic fevers of a not very violent character, according to Von Hildenbrand". (Organon, §36). ${ }^{10}$

In the current situation of COVID-19, if the chronic miasmatic disease is generating a more intense reaction in the body than what the acute epidemic disease can generate, intense manifestations of this second disease will not be observed, even if viral particles are found in the secretions of the individual by laboratory techniques. The two conditions (chronic disease and COVID-19) are dissimilar and the chronic disease is the "stronger," as described by Hahnemann. ${ }^{10}$

2. "Or the new dissimilar disease is stronger. In this case the disease under which the patient originally labored, being the weaker, will be kept back and suspended by the accession of the stronger one, until the latter shall have run its course or been cured, and then the old one reappears uncured. Two children affected with a kind of epilepsy remained free from epileptic attacks after infection with ringworm (tinea) but as soon as the eruption on the head was gone the epilepsy returned just as before, as Tulpius ${ }^{10}$ observed. The itch, as Schöpf saw, disappeared on the occurrence of the scurvy, but after the cure of the latter it again broke out. So, also the pulmonary phthisis remained stationary when the patient was attacked by a violent typhus but went on again after the latter had run its course. [...] And thus it is with all dissimilar diseases; the stronger suspends the weaker (when they do not complicate one another, which is seldom the case with acute diseases), but they never cure one another". (Organon, §38). ${ }^{10}$

If the secondary disease (COVID-19) has the capacity to generate a more intense reaction of the organism in comparison to the pre-existing chronic miasmatic disease, it is because this previous chronic disease is "weaker" than the secondary disease. The disease that previously afflicted the patient, being milder, will be contained and suspended by the "stronger," until the latter is extinguished or cured, and then the original uncured disease reappears. ${ }^{10}$ In this case, the individual would present the typical clinical picture of COVID-19 with symptoms varying in intensity according to the individual's vitality, and after the pneumonia condition has been resolved, or when the organism is in a period of convalescence, manifestations of an exacerbated chronic disease may appear, which sometimes end up being attributed erroneously to the epidemic.
3. "Or the new disease, after having long acted on the organism, at length joins the old one that is dissimilar to it, and forms with it a complex disease, so that each of them occupies a particular locality in the organism, namely, the organs peculiarly adapted for it, and, as it were, only the place specially belonging to it, while it leaves the rest to the other disease that is dissimilar to it. [...] As two diseases are dissimilar to each other, they cannot remove, cannot cure one another. [...]". (Organon, §40). ${ }^{10}$

In this third situation, the two dissimilar diseases co-exist, and the individual has manifestations of both conditions. Due to the acute worsening by COVID-19, a worsening of chronic illnesses may develop. It is in this situation that reports of patients with cerebrovascular accident, acute myocardial infarction or renal failure appear, for example, in the presence of the classic clinical picture of COVID-19.

The presence of chronic miasmatic diseases in the population exposed to COVID-19 may be a limiting factor of severe epidemic disease manifestations in most individuals, but chronic conditions may be exacerbated in some patients. These consequences will depend on the initial form of response that the organism was generating to this already existing chronic disease. Those who will die will be the most susceptible, which excludes most of the population; other individuals have a favorable prognosis and good recovery.

When understanding the influence of chronic miasmatic diseases in this process, one must decide to act by treating and controlling them; otherwise, either the chronic disease will persist through its natural course or there will be an exacerbation of the process, ${ }^{7}$ causing different manifestations of the COVID-19 condition and consequent worsening of health status, altering the individual's vitality, which can lead to death.

\section{Conclusion}

The intensity and severity of the COVID-19 condition depends on the way in which a previous chronic miasmatic disease is manifesting in the individual, and may have important repercussions on other organs, determining symptoms that predominate over classic COVID-19, resulting in varied clinical conditions in the face of the same cause (SARS-CoV-2). The evolution depends both on the body's response to the stimulus caused by the disease and on the individual's vitality, including his/her immune status. Therefore, one must act on the treatment and control of chronic miasmatic diseases, as these can interfere positively or negatively on the evolution of the affliction, depending on each individual's response.

\section{Highlights}

- The presence of a chronic miasmatic disease influences the manifestation of COVID-19.

- An individual's reaction to SARS-CoV-2 depends on the type of response to the chronic miasmatic disease.

- The association between a chronic miasmatic and an epidemic disease causes different reactions according to their relative intensity.

- Treating chronic miasmatic diseases during an epidemic to avoid negative interference in the process is of extreme importance. 


\section{Conflict of Interest}

None declared.

\section{References}

1 Gorbalenya AE, Baker SC, Baric RS, and the Coronaviridae Study Group of the International Committee on Taxonomy of Viruses. The species Severe acute respiratory syndrome-related coronavirus: classifying 2019-nCoV and naming it SARS-CoV-2. Nat Microbiol 2020;5:536-544. Doi: 10.1038/s41564-020-0695-z

2 Brasil. Ministério da Saúde Protocolo de Manejo Clínico da Covid-19 na Atenção Especializada Brasília. 2020. Available at: https://portalarquivos.saude.gov.br/images/pdf/2020/April/07/20200407ProtocoloManejo-ver07.pdf. Accessed April 10, 2020

3 Centers for Disease Control and Prevention. Infection Control Guidance for Healthcare Professionals about Coronavirus (COVID19). Available at: https://www.cdc.gov/coronavirus/2019-ncov/ hcp/infection-control.html. June 3, 2020

4 Patel AB, Verma A. COVID-19 and angiotensin-converting enzyme inhibitors and angiotensin receptor blockers: what is the evidence? JAMA 2020;323:1769-1770
5 Rezende LFM, Thome B, Schveitzer MC, Souza-Júnior PRB, Szwarcwald CL. Adultos com alto risco de doença grave por coronavírus-2019 (Covid-19) no Brasil. Rev Saude Publica 2020; 54:50

6 Hahnemann S. Doenças crônicas-sua natureza peculiar e sua cura homeopática. 8th ed São Paulo: Grupo de Estudos Homeopáticos de São Paulo (GEHSP) "Benoit Mure"; 2020

7 Hahnemann S. Exposição da doutrina homeopática ou Organon da arte de curar. 7th ed São Paulo: Grupo de Estudos Homeopáticos de São Paulo (GEHSP) "Benoit Mure"; 2019

8 Hahnemann S. Doenças crônicas-sua natureza peculiar e sua cura homeopática. 8th ed São Paulo: Grupo de Estudos Homeopáticos de São Paulo (GEHSP) "Benoit Mure"; 2020:77

9 Hahnemann S. Exposição da doutrina homeopática ou Organon da arte de curar. 7th ed São Paulo: Grupo de Estudos Homeopáticos de São Paulo (GEHSP) "Benoit Mure”; 2019: 11-19

10 Hahnemann S. Exposição da doutrina homeopática ou Organon da arte de curar. 7th ed São Paulo: Grupo de Estudos Homeopáticos de São Paulo (GEHSP) “Benoit Mure”; 2019: $35-40$ 